\title{
"Evaluation of Sewing Performance of Plain Twill and Satin Fabrics Based On Seam Slippage Seam Strength and Seam Efficiency
}

\author{
G.Seetharam, L.Nagarajan \\ M.Tech, Department of Textile Technology, Jaya Engineering College ,Thiruninravur-602 024
}

\begin{abstract}
Seam strength is an important factor in determining the durability of a garment. Seam strength is determined by resistance to pulling force and abrasion. Seam tenacity break the fabric or the weakest stitch of seam. Seam abrasion resistance is the amount of rubbing action needed to wear away stitches in the seam strength is related to stitch type, thread strength, thread tension, seam type,seam efficiency, width, and stitches per inch.Loop strength of thread is more important to durability the seam need not be stronger than the fabric being sewn.A triple stitched lapped seam would not be necessary for a pair of corduroy jeans since the fabric itself is not strong and would wear out before the seam.It is better to have the thread is an overstressed seam that to damage the fabric.Our project objective is to find the seam of strength by using different type of materials.
\end{abstract}

\section{Introduction}

Seam failure in garment can occur because of either the failure of the sewing thread leaving the Fabric intact or fabric rupture, leaving the Sean intact or both breaking at the same. Seam strength is testing in almost the same manner as fabric breaking and strength.

The strength of a seam or stitching should equal that of the material in order to have balanced construction that will withstand the forces encountered in the garment of which the seam in a part.

The elements affecting the strength of a seam or stitch type thread strength type thread strength stitches per Inch, Thread tension, seam type, seam efficiency of the material. Generally a seam made with chain stitch will be stronger than the seam made using lock stitch.

Obviously stronger the sewing thread, the stronger the seam higher number of stronger the sea, higher number of stitches per inch. Up to a point will give higher seam strength but too many stitches per inch will weaker the fabric so seam may stay intact but the fabric many rupture resulting in seam failure. Higher thread tension will give higher seam strength but to high a thread tension will result in seam puckering. Lap felled seam will be stronger than lapped seam. Fabric with higher seam efficiency will provide stronger seam than fabric with lower seam efficiency.

Seam efficiently is seam strength expressed as \% fabric breaking strength.

The elasticity of a stitching should be slightly greater than that of the material which it joins .so that the material will support its share $f$ the forces encountered in the end use of the garment .The elasticity of a seam or stitching depended on the stitch type and thread elasticity.

Seam in woven fabrics: When garment seams are subjected to increasing transverse ,a point is reached when the threads of the fabric which lie parallel to the seam in the "Seam allowance" are slightly and present and unacceptable appearance such a seam has "failed" commercially even though no rupture has occurred in any examination of sea, attending has to be directed to two different values of stress ,namely that at which the seam opens to an unacceptable extent , and that at which it finally ruptures.

The opening load is mainly dependent on:

- $\quad$ The stitch rate

- $\quad$ The weave structure of the fabric

- The width of the seam allowance

The width of the seam fabric allowance, the seam opening and breaking loads were both found to increase rapidly with stitch rate, the effect being most marked with plain weave structure thus an arrow Sean allowance can to some extent be offset by increasing the stitch rate.

In is minimum sewn knot (or loop) strength of the sewing thread that governs seam strength, and not the mean tensile strength measured directly from the cop or bobbin.

When stress is applied to a seam at right angles to list length the load is carried by the intersecting loops of the sewing threads, and when the latter rupture, the fabric occurs at the opening of the loop. The strength parameter that applies in therefore the loop strength rather than the straight tensile strength of the sewing thread. 


\section{1 seams}

\section{Literature Review}

A seam is the application of a series of stitches or stitch types to one or several thickness of material .Seam line is a stitch line of a seam; it is usually parallel to and always a appearance of the seams affects overall attractiveness of a garment. Straight, neat ,smooth ,even seams that are not twisted ,ropey ,or rippled contribute to aesthetics.

\subsubsection{Classification of Seams}

\subsubsection{Class 1-The Super Imposed Seam}

The superimposed seam is the most commonly used method of seaming; however its overall appearance can be very different when all the necessary factors have been balanced. The basic characteristic of a superimposed seam is that the seam allowance is exactly the same on top and bottom ply.

\section{The Plain Seam}

The most basic seam can be used efficiently on straight, curved or angular seams equally well, but the skill level of the operative will vary depending on the intricacy of the seam

This type of seam will require some form of neatening. The quickest method will be utilizing one of the over lock machines, the 2or 3 thread type being the most normal. The choice is dictated by the laundering techniques, as previously discussed in the stitch types section.

Another consideration is whether the appearance of the garment is the most important factor or the garments durability. If the garment accessitates a "tailored appearance" then the seam allowances will need to neaten separately allowing the seam allowances to be pressed open, which will provide a smooth flat appearance.

However if the garment is likely to be subjected to hand wear then the over locking of the seam allowances together will help to give stability to seam and increase the strength and durability of the seam. This particularly useful in the manufacture of shirts, blouses, pajamas and work wear type of garments.

If the garments are being produced by "out workers "the over lock facility may not be readily available, and so the "cap edging" technique may be more practical as this performed on the lock stitch machine. This involves the raw edge of the seam allowances being folded to the wrong side of the fabric and being stitched along the folded edge to hold the fold securely. This technique provides stability and allows the seam to lie flat. Because of the fold of the fabric, this, method of neatening tends to be rather bulky and therefore unsuitable for bulky fabrics. Also the width of seam allowance needs to be increased to allow the neatening to lie flat.

Both over locking and cap edging techniques are easily produced and require minimum skill level. However both techniques would be unsuitable for fabrics of a sheer or semi-sheer structure as the seam.

Allowance and its neatening would be visible on the right side of the garment which would obviously impair the appearance of garment.

If the seam is to include a decorative feature such as a piping or lace insertion, the construction of the seam is exactly the same with the inclusion of the trimming. When including such items care must be taken to avoid unnecessary bulk, which can cause seam pucker therefore impairing the appearance of the finished garment. Another factor worth consideration is will the trimming launder at the same rate (will it dry) as the rest of the garment.

Another decorative feature is to top stitch the seam, with either self colored thread or one of a contrast color. When choosing this type of finish it is imperative that the machinists have the necessary skill level in order to meet the quality requirements of the finished garment as attention is being drawn to the feature and therefore needs to be of a good quality. An advantage of top stitching through a seam is that6 it can help to give extra strength and stability to the seam, e.g. the crotch seam of a pair of trousers can be greatly improved y using this very simple technique.

\section{The French seam}

Which is superimposed seam is self - neatened and overcomes the problem of showing the neatening through the structure of the fabric. This seam is performed trapping the raw edges in between the two rows of stitching. This seam type is also useful when utilizing out-workers as it is possible for the garment to be virtually completed by the one machinist, providing the skill level of the operative meets the quality requirements of the employing company. And subsequent customer

The French .seam is useful for garments which require regular laundering, e.g. children's, wear as its self neatening characteristic lends itself to stringent laundering techniques.

The French seam is also useful for the out-worker as seams can be neatened as the garments is being assembled. However it is limited to straight and slightly curved seams, as steep curves and corners would be extremely difficult to perform 


\subsubsection{Class 2 lapped seam}

The seams in this have uneven seam allowances; therefore the pattern cutting and garment assembly has to be performed with extra care to ensure that the garment fits together correctly. In a nut-shell the seam allowance on one side overlaps the other, hence the name lapped seam.

\section{The Raised seam}

The raised seam is the simplest of lapped seams, and is often used in the seams of skirts, trousers and some jackets and coats where interest is built into the seams as a decorative feature, enhancing the style lines of the garment. The seam needs two rows of stitching in its construction as well as some form of neatening, normally of the lovelock type. This type of seam is normally performed on medium to heavy-weight fabrics as the bulk of the fabric helps to crate the raised effect that this type of seam is characterized by. The raised seam is also referred to as the welt or welted seam. To reduce confusion within a company the use of the British classification system can be an advantage, however if everyone understands that all the names refer to the same seam, type the terminology can be sufficient.

\section{The loose raised seam}

The Loose Raised seam is basically the same as the raised seam with the addition of another row of sewing which allows the second row of sewing to be removed, which gives the loose fold which the seam is characterized by. As with the raised seam the raw edges need to be neatened. This type of seam is used mainly to provide interest in outer coats, the camel coat being the most obvious.

It can also be used where two loose raised seams face each other to form.

\section{The channel slot seam}

The channel- slot seam is normally used on medium to heavy-weight fabrics and is of a decorative nature. The seam can be used to open out a pleat where the seam / pleat backing is of a contrast color, therefore adding extra interest to the style line. When using seams such as the raised and channel-slot type, the degree of accuracy demanded of the machinist is increased. Therefore higher skilled work- force is necessary to produce these seams opposed to the plain variety.

\section{The Flat Felled seam:}

The Flat Felled seam is also referred to by several names, lap felled and twin needled seam beam being the most common. The term twin needled can however be miss-leading and should be avoided, as a twin needled machine can be used for many other applications. The flat felled seam is used on various weights of fabric and types of garment all of which tend to be of hard wearing functional type, or subjected to stringent laundering techniques. The

Types of garments can range from denim corduroy obviously needing greater seam allowances in order that the garment will survive the hard wear, which it is likely to be subjected to. The lighter weight cottons used in the manufacture of shirts or pyjamas do not have the bulk of the heavier fabrics and therefore need a reduced width to gain the best appearance in the finished garment.

As the flat felled seam is self-neatening this helps to give the garment good laundering qualities, and minimum care when it needs to be pressed as the turnings are conveniently tucked inside the seam. The seam can be performed manually but will take the machinist twice as long as the twin needled machine with folders, as the two rows of sewing will need to be worked separately, therefore increasing the machinist handling time, and subsequent costs.

\section{The roll seam}

The roll seam or Mantua markers seam is very similar to the French seam in the super imposed class, but it is performed by using one row of stitching therefore reducing the machinist handling time and thread consumption. Its uses are the same as the French seam but it has to be said that by reducing the rows of stitching the strength of the seam is obviously reduced.

\subsubsection{Class 3 bound seam}

This class differs from the previous two as it is finishing the raw edge of fabric with a second piece of material, therefore neatening the edge of seams necklines, hemlines, cuffs etc. sometimes the bindings are of a contrast material to give extra interest. The bindings can be applied by manual methods or by utilizing folders that help to de-skill the job of machining. By using aids and attachments the process is often speeded up therefore reducing costs as well as producing a standard finish to the garment, ensuring a good quality if used properly. If the binding material is of a non-fraying nature then the simplest binding may be used as below. 
Where the binding is prone to fraying two extra folds of material need to be made to ensure the binding performs to the requirements of the garment.

However the above binding technique is not suitable for all materials as too much bulk may be created and cause an unsightly finish to the garment. To reduce the risk of unsightly bulk one edge of the binding could be over locked to allow the binding to lie flat as the next diagram shows.

The type of bindings used would vary according to the type of garment being produced. The most popular type of binding is of the bias type which will allow straight, curved and even angles to be successfully finished by this technique. The use of ribbon or pairs bindings limits them to straight seams as the rigidity of the ribbon type fabric makes it difficult to bend around corners. The quality of the finished garment will dictate the quality of binding used. In men' $\mathrm{s}$ trousers knitted nylon bindings is both practical and hard wearing whereas satin bindings used in unlined jackets are not just functional but used to crate interest.

\subsubsection{Class 4 flat seams}

In this class the seams are performed with the plies of fabric being laid side by side, and the seam then links the two ply' s together to form a join, hence the term flat seam as the fabric is butted together, not laid one ply on Top of the other. This type of seam is most commonly used on knitted fabric as the risk of unraveling in knitted materials is likely than woven fabrics. However where the edges have less been pre-neatened woven fabrics can be used. The advantage of using a flat seam is worn next to the skin, such as underwear and sportswear. The machinery used to perform this type of seam can be of the lockstitch zigzag variety or more recently or more recently the use of cover seams of the 400 class are becoming more efficient and economical and economical to produce.

The fact that there is no seam allowances also in advantage when it comes to laundering as the seam will readily dry at the same in advantage when it comes to laundering. This method of seaming can be used to attach bindings to curved edges such as collars, armholes and stitched into panels. However to use this type seaming in this way, requires machinists of a higher skill than the normal seaming techniques. Obviously the cost of such labor would increase the cost of the garment and therefore the price point of the garment must be considered carefully before embarking on this technique.

\subsubsection{Class 5 decorative stitching}

This class includes stitching that is incorporated into design of the garment. The stitching can be of the single needle type or more normally multi-needled. It is used to great effect when attaching lace, ribbons, braid and embroidery, of the smocking type, on children's wear and lingerie. Pin tucks also are included in this class, and when produced by multi-needled machine the quality is assured as well as being performed in the minimum of time, therefore the expense of special machinery can be re- coupled in a short space of time. Another advantage of using such machinery is that the machinist job de-skilled, making it easier to train personnel to perform what used to be highly skilled jobThe use of pin-tucks in a garment gives the garment design interest which is added expense to the more functional garment and therefore must conform to the price point and quality standard of the company profile. Normally pin-tucks are used in more up-market garments and so the added expense is not necessarily a problem. The list of stitching in this class seems endless, with a new designation for each width of ribbon, tape etc. and so where specific classifications are needed reference to the international standards stitches and seams booklet part two is advisable.

\subsubsection{Class 6 edge neatening:}

In this class neatening of the raw edge of the fabric is covered, but not bindings as these have already been covered in class 3 . The simplest method in this class is that of the over lock. Refer to superimposed seams for uses of over locking, i.e. plain seam.

\subsection{Stitch}

The term stitches refers both to the thread interloping or Interlocking used to make seams-the joints between two pieces of fabric that are sewn together. Stitches help determine the functional aesthetic performance of a garment. Their durability comfort and attractiveness are important performance considerations determined by the end use and design of the garment, the type of fabric used, and the location and purpose of the stitches. Cost considerations also affect the choice of stitches.

\subsubsection{Stitch types}

Class 100- This class consists of a stitch formation which involves a single thread being looped through itself to form a chain. Sometimes there Can be more than one thread, but the formation of the chain is such, that it does not interlock and therefore is likely to unravel if the loop is broken. For applied it is prone to come undone. 
Class 200 - This class of stitches are worked by hand. The nature of hand worked stitches make them expensive to produce and therefore unsuitable for bulk production. However for high class production-made to measurehand stitches may be used to enhance the finish and sometimes the performance of specific garments. Some small companies may use hand stitches to perform particular jobs i.e., sewing buttons, this can reduce the high costs of machinery and maintenance.

Class 300 -This class consists of a stitch formation which involves a minimum of two threads locking together in the centre of the plies of fabric being sewn, hence the name lockstitch. This stitch type is more secure than the 100 class as its locking mechanism reduces the tendency for the stitch to unravel.

Class 400 -This class is worked with a minimum of two threads which inter-loop to make the stitch more secure than the 100 class. Because of the looping mechanism this stitch class is often referred to as the double lockchain stitch, as the threads do lock around each other giving the effect of a locking mechanism. This stitch if broken in the loping action will unravel therefore care should be taken not to break the stitch at its point of looping .

Class 500-This class consists of stitches worked around the edge of the fabric, and can be worked around the edge of the fabric, and can be worked with one or more threads. Because this stitch is worked around the edge of the fabric it is often referred to as the over lock stitch. Tailors sometimes refer to this stitch as surging

12

Class 600 - This class of stitches consists of stitches that caver the fabric being stitched and are worked with a minimum three threads. The characteristic of the stitch lends itself to its name, cover stitch.

Within each stitch classification there are different stitches which are given their specific designations with the last number, i.e. 301 is the basic lockstitch machine. The 300 denotes the machine belongs to the lockstitch class the 1 denotes that the stitch mechanism is of the most basic type available. Because there are many variations, for the purposes of this course we are confirming our study to the main types of machinery used for garment manufacture.

\subsubsection{Class 100 Stitch Classifications}

101 this stitch formation can be adapted for many different uses. Tailors use this stitch formation for various machine types. It can be used as a tacking/basting machine. This type of machine would employ a large stitch as it is only a temporary stitch to allow the tailor to fit the garment or hold parts together until the next operation is performed. The use of a soft cotton enables the thread to be removed easily without causing damage, as the threads of the fabric will close up, when the fabric is pressed.

The stitch formation can be adapted so that the tailor can pad the collar and lapels of ladies and men's jackets and coats.

Because of the nature of the chain mechanism stitching can only be sewn by continuous stitching. Therefore is no facility to start and finish in the middle of a seam as the chaining mechanism will be lost and therefore unravel.

103: This stitch type is used specifically to hold hams in position. The advantage of this stitch is that it not visible on the right side of the garment therefore produces a superior appearance than some of the other stitch types. However, because of its chain formation it is possible that if the loop mechanism is broken the stitch will unravel. It is not always reliable if used in garments which need constant laundering i.e. children's or work clothes, as in overalls.

This stitch type is used when the hem needs to be as unobtrusive as possible. When used on woolen skirts, men's trousers, jackets and coats a smooth appearance is gained on the right side of the garment. On a medium weight fabric an "all stitch" may be used which means every stitch is picking up fabric or a loosely woven fabric is being sewn, the picking up of the garment ply may be "skipped" this avoids leaving an impression on the right side of the garment. Depending on the weight and construction of the fabric being sewn up to 5 stitches mat be skipped, the disadvantage of missing so many stitches is that the hem could easily be caught and pulled down.

Sometimes this type of machine is referred to as a "blind hammer" or a "skip stitch" both are self explanatory as the stitch should be "blind" to the right side and is capable of performing "skip" stitches.

Other machines in this stitch classification can be used to work buttonholes, automatically. By this I mean that garment is positioned in the machine, the operative sets the machine into action, the sides, and ends are worked and the hole is cut in the one operation. This produces a buttonhole quickly and cheaply and the training of the operative is also cost effective. 
Button-sew machines can also be of the single chain stitch type. The disadvantage again, is that the stitch type. The disadvantage again, is that the stitch is likely to unravel if the thread is broken in the looping mechanism. This factor can lead to customer dissatisfaction as buttons tends not to stay secure for the lifetime of the garment production.

\subsubsection{Class 200 Stitch Classifications}

As this class refers to stitches worked by hand, its use is limited to the more expensive end of the garment production. However hand stitching is valid where the extra cost is not a problem and where the finish look takes priority.

\subsubsection{Class 300 Stitch Classifications}

301: This stitch is the most basic of all the lock stitch formations. It is formed with a single needle thread and a single spool/bobbin thread, which locks in the centre of the layers of fabric being stitched together.

This stitch type is still the most extensively used within the clothing industry. For garments using woven materials, provided the right type of thread is used, then lockstitch provides enough strength in the seams, for the garment to its last expected lifetime. Care must be taken to ensure that a correctly balanced stitch is formed, as a loose or tight tension will cause friction within the seam during wear, resulting in seam failure. Also incorrect tensions can spoil the finished look of the garment.

A loose tension will allow the seam to grin, and may even alter the fit of the garment. A tight tension will tend to pucker the seam, which will only be released by unpicking and re-stitching with a balanced stitch.

Seams in stretch would tend to be unreliable, if stitched with a lockstitch machine as the length of thread within the seam is only marginally more than the length of seam. Therefore any stretch greater than the length of thread within the seam is likely to break down, particularly if the garment is to be laundered regularly, as the laundering technique can weaken the threads within the seam.

This stitch provides a seam which will press open, as the stitch structure is the same on both sides of the stitch. Other stitches tend to be bulky on one side therefore limiting the flattening of the seam and restricting the smooth appearance on the right side of the garment.

The lockstitch is also ideal for use when top - stitching, as the accuracy in pivoting corners on pockets and collars is second to none, providing the skill of the machinist is up to standard. The training of machinists for the lockstitch machine can be a lengthy business to allow the trainee to reach an acceptable standard of quality, and speed for the production unit. The use of programmable units such as the I.SU.[Integrated Sewing Units] can help to reduce training time and also provide a standard finish, thus improving quality.

The use of back - tacks, [where the seam is stitched for $3-4$ stitches reversed to repeat the stitch and then stitched again as the seam is continued] are necessary to strengthen the beginning and end of a seam to ensure that the seam will stay secure, for lifetime of the garment. Sometimes condensed stitches are used to reduce the effect of bulkiness, but care must be taken not to burst the fabric threads as this will weaken the seam not strengthen it.

\subsubsection{Class 400 stitch classifications}

401: this is the most basic of the double lock chain stitches. This stitch is formed with a minimum of two threads. The needle thread is passed through the fabric and then interlaced and interloped with the lopper threads.

Because of the extra thread used in this stitch formation extra extensibility is built into the seam. This extensibility can be increased by using threads that will stretch and recover with the movement of the seam as it is worn As the chaining action place on the underside of the stitch tends to be rather bulky, this restricts the smooth pressing of the seam. This stitch characteristic makes it unsuitable for garments that require a tailored appearance, although there are exceptions to this rule

However where the seam is to be neatened with the seam allowances are over locked together, this stitch will provide strength and extensibility, e.g. sweat- shirts, track straight from the package rather than filling spools/ bobbins is that the operative can spend more time actually sewing.

This stitch will not back- tack, the chaining action would be lost and therefore could unravel due to the chain not being locked into position. Where the seam is to be trapped by another row of stitching the seam will normally be secure, but the use of a bar- tack particularly on jeans and work wear would ensure that the stitching would last the garments life expectancy

This stitch however is prone to grin therefore it is essential to determine what is acceptable to the buyer/customer, before large scale production is commenced. 


\subsubsection{Class 500 Stitch Classifications}

501: This is a single thread stitch, which is formed around the edge of the fabric .It is used where the very edge of the fabric is stitched; therefore, it is only suitable for materials, which do not fray.

Leather and suede gloves/mittens are often sewn with this machine as it uses a fine seam allowance, therefore providing a close fit without impairing the comfort of the wearer.

It is also useful when seaming fur skins of fur fabric with a knitted backing, a the fur pile can be pushed out of the way of the needle thus avoiding trapping the pile into the seam.

512: This stitch seam 7 neatens in one operation, therefore saving on machinery, maintenance and labor. This stitch is often referred to as the simulated safety stitch, as it seams and neatens in the one operation .Quick and easy to perform and is economical in maintenance.

Suitable for light weight to heavy weight production, shirts, blouse, lingerie, children's, wear, swim wear, leotards, track-suits, sweat-shirts, and denim and cord jeans.

This stitch obviously produces a closed seam, as the seam allowances are stitched, together ,this given a hard wearing finish and is particularly suitable were regular laundering techniques are necessary .This finish is not always acceptable ; men's trouser is one such case where a reasonable quality is necessary ,therefore an open seam is more satisfactory .However for boy's /youth's trousers the finish is acceptable because the appearance is out -weighed in preference to a practical and hard wearing finish.The usage of the same as the 512 , configuration is however slightly different.

\subsubsection{Class 600 Stitch Classifications}

This stitch type is performed with a minimum of three threads. All stitches in this classification have the characteristic of covering the seam which it is sewing. Three stitches were developed primarily to strengthen seams, and in some cases improve the comfort of close fitting garments. The classic example of both these characteristics is in the production of wet suit, where the closeness of fit and the strength of seam are essential properties within the garment.

When used in T-shirt and sportswear manufacture the seam is often stitched with a 504 over lock, and then cover -stitched to provide a flat seam which will not rib/irritate the wearer .Thos is particularly important for the active sportswear market.

\subsection{Seam Quality}

The characteristics of a properly constructed seam, depends on the fabric and must take into account the following factors:

- $\quad$ Strength

- $\quad$ Extensibility [ including elasticity]

- $\quad$ security

- $\quad$ Durability

- $\quad$ Appearance

\subsubsection{Strength}

A seam must be strong, the criteria being maximum strength for minimum thickness and economy of sewing thread. Seam strength has to be measured in two directions:

- $\quad$ Lateral - across the seam

- $\quad$ Longitudinal - along the length of the seam

\subsubsection{Lateral}

This refers to the free edges of material, the seam allowances or turnings are important .If the width of seam allowance is too narrow the seam may pull apart, if the fabric is sewn has a tendency to fray.

The strength may be increased by:

a) Using larger turnings

b) Using a stronger thread

c) By increasing the number of stitches per $\mathrm{cm}$.

[Care should be taken to bulkily stitched seam] 


\subsubsection{Longitudinal}

The strength along the length of the seam is closely related to the extensibility of the seam, as insufficient strength will result in "cracking" during wear. This is particularly important when sewing jersey fabrics with a high degree of stretch

\subsubsection{Extensibility}

This property is required in all seams, but varies according to the fabric being sewn. If a garment is being made of a material with a rigid characteristic, the seams will require little stretch, therefore a lockstitch 301 , would be suitable in most cases.

Sweaters, cardigans or jumpers, using extensible fabrics will need extensible seams, as the seams need to stretch as much as the fabrics being sewn therefore the over lock class is more generally used. However where stability is required to help maintain the garment shape, the 401 chain stitch is advisable. When producing ladies structured garments and dress wear, the fabric tends to be pliable which can result in the seaming breaking down during wear. Because the seam is required to give with the movement of the body, extensibility must be built into the seam to ensure that the seam will perform satisfactorily during wear. A number of factors need to be considered in the case:

- $\quad$ Thread extensibility

- $\quad$ Stitch

- $\quad$ Seam type

End use of the garment, when studying these factors a balance is sometimes necessary. The optimum stitch may be the 3 or 4 thread over lock but this would not allow the seam to be pressed flat and therefore impair the look of the garment. Therefore the seams used may vary within a garment depending on where the stresses originate and the look of the garment.

\subsubsection{Durability}

A seam must be durable and last the life expectancy of the garment, this must include the laundering technique in order to confirm to the trade description act. The following factors must be considered in order to ensure the seam will perform satisfactorily during wear;

- $\quad$ Thread type

- $\quad$ Stitch type

- $\quad$ Seam type

- $\quad$ Fabric type

- $\quad$ Fiber content

Laundering technique, a wrong choice of any of these factors can result in friction wearing away the threads within the fabric or the stitching technique.

\subsubsection{Security}

Security is closely connected to durability, with the addition of ensuring that the stitching within the seam is fixed securely at the beginning and end of each row of sewing. A lockstitch seam can be easily backTacked Whereas the ends of a chain or over lock seam needs to be trapped into another seam or bar-tacked to ensure that the seam will not unravel.

\subsubsection{Appearance}

Often the appearance of the seam is overlooked, but sometimes the optimum strength of a seam needs to be re-assessed as the look of the garment may be impaired by the use of a bulky unsightly looking seam. Another factor to consider when assessing the appearance of the seam is that the machinery has been set up correctly, a puckered seam will instantly spoil the hanger appeal of what could have been an attractive garment. Blunt needles not only weaken the strength of a seam but also can distort the weave or knitted structure of the fabric, which again will impair the finished look of the garment.

\subsection{SEAM FAILURE}

Five factors that determine that determine the strength of a seam include:

- $\quad$ Fabric type and weight

- $\quad$ Thread fiber type, construction, and size

- $\quad$ Stitch and seam construction.

- $\quad$ Stitches per inch

- $\quad$ Stitch Balance. 
Any one of these factors can adversely affect the performance of a sewn product depending on the end -use of the sewn product. Following are a few general comments related to the factors listed above.

\subsubsection{Fabric type and weight}

Fabric type and weight can affect seam performance depending on the following:

- $\quad$ Fabric content (100\% cotton, cotton/polyester blend, nylon).

- Fabric Construction:

- Woven or knit.

- $\quad$ Type of weave used(plain, twill, jersey, tricot)

- $\quad$ Fill count.

- $\quad$ Yarn type and size.

- $\quad$ Pattern placement and seam direction.

- $\quad$ Propensity of the yarns in the seam to shift or pull out of the seam.

- $\quad$ The fabric to determine its strength we cannot specify seam strength requirements that are stronger than the fabric itself.

\subsubsection{Thread fiber type, construction, and size}

These all have a definite effect on seam strength including the following factors:

\subsubsection{Fiber type}

Some fibers are stronger than others and have greater loop strength contributing to greater seam strength. For example, a 100\% spun polyester thread will give greater seam strength than a $100 \%$ cotton thread of the same size.

Synthetic fibers like polyester and nylon are much more resistant to abrasion and chemical degradation (Such as bleach) than cellulosic fibers. Cellulosic fibers on the other hand have superior heat resistance.

\subsubsection{Thread Construction (Spun, Core, Textured, Multifilament, etc)}

- $\quad$ Core threads, made with continuous filament polyester core, generally will provide higher seam strength than spun and textured threads.

- $\quad$ Continuous filament polyester or nylon thread constructions will provide greater resistance to abrasion and seam degradation.

- $\quad$ Some thread constructions are less subject to shearing or cutting each other when interloped together in the seam. Air entangled, textured, and monochord thread constructions exhibit the best loop strength characteristics.

\subsubsection{Thread finish (Soft, mercerized, glace, and bonded, etc)}

- $\quad$ Glace or bond finished threads generally has superior abrasion resistance to soft finished threads.

- $\quad$ Mercerized threads are stronger than soft cotton threads of the same fiber type and size.

\subsubsection{Thread Size (tex, metric, yarn size)}

Given a specific fiber type and thread construction, the larger the thread size, the greater the seam strength. As previously mentioned, different fiber types and thread constructions have different loop-strength Characteristics. In many cases, a smaller thread size will imbed itself in the seam making it less prone to surface abrasion.

\subsubsection{Stitch and seam construction}

\section{Stitch types:}

- Generally, the more thread consumed in a stitch, the greater the seam strength. This holds true when comparing 301 lockstitch seams to 401 chain stitch seams.

- $\quad$ Threads used in 301 lockstitch seams are more susceptible to shearing each other than 401 chain stitches and 504 over edge seams because of the way the threads are interlocked together rather than interloped together.

\section{Seam types:}

- Many seam constructions are more resistant to both stress and abrasion than other constructions. For example, ISO 49162.04 felled seam is the strongest of all seams because the stress is shared by the fabric and the thread. 


\section{Stitches per Inch}

Generally, the greater the number of stitches per inch in a seam, the greater the seam strength. This refers beck to the point that the more thread you put in the seam, the stronger the seam. However, on some fabrics,, too many stitches can cause damage to the fabric by cutting the yarns enough to weaken it.

Excessive stitches per inch can also contribute to seam puckering and reduce the speed through the machine resulting in loss of production.

\section{Stitch Balance}

As a rule, the more thread that can be put into seam, the greater the seam strength. This can be accomplished by adjusting the sewing machine thread tensions, thread control guides and eyelets etc.

Care should be taken not to put too much needle thread in the seam to cause the seam to "grin" or open up when stress is applied to it.

Excessive sewing machine thread tension will cause reduced seam strength as well as create other sewing problems.

\section{Seam Efficiency:}

Measurement of the seam quality was done by studying the seam efficiency, seam puckering. Seam efficiency was calculated using the following formula :

Seam Strength Tensile (\%)

Seam efficiency $(\%)=\quad X 100$

Fabric Tensile Strength

\subsection{Material Purchase}

\section{Materials And Methods}

The material Selected for the experiment is 100\% cotton, polyester and silk the fabric parameters GSM wrap count and weft count EPI and PPI and weave details are given in the table in 3.1

Table 3.1 Fabric Selection for the Experiment

\begin{tabular}{|c|c|c|c|c|}
\hline S.No & RAW MATERIAL & \multicolumn{3}{|c|}{ SPECTFICATION } \\
\hline 1 & Fiber & Cotton & Polyester & Silk \\
\hline 2 & Weave & Plain & Plain & Plain \\
\hline 3 & GSM & 112 & 103 & 40 \\
\hline \multirow{3}{*}{4} & Count & \multirow{2}{*}{43 s Count } & \multirow{2}{*}{ 84.5 Denier } & \multirow{2}{*}{50 Denier } \\
\hline & Warp count & & & \\
\hline & Weft count & $40 \mathrm{~s}$ Count & 80 Denier & 38 Denier \\
\hline \multirow{3}{*}{5} & Density & \multirow{2}{*}{120} & \multirow{2}{*}{126} & \multirow{2}{*}{124} \\
\hline & EPI & & & \\
\hline & PPI & 78 & 88 & 160 \\
\hline 6 & Sample Size Length*Width inches & $8 \cdots 4 *$ & $8^{\prime \prime * 4 "}$ & $8 \cdots 4 " n$ \\
\hline
\end{tabular}

\subsection{The Seam Sample Size}

The sample size is taken on the basis of tensile strength tester gauge length $33 \mathrm{cms}$ and $10 \mathrm{cms}$ width. The lapped seam is applied for making all the samples the selection of the machine, machine speed, SPI, given in the table 3.2 
Table 3.2 Sewing Condition for Experiments

\begin{tabular}{|l|l|l|l|}
\hline \multicolumn{1}{|c|}{ SEWING PARAMETERS/TYPE OF MACHINE } & \multicolumn{1}{|c|}{ SNLS } & FLAT LOCK & \multicolumn{1}{c|}{ FEED OFF ARM } \\
\hline Type of Stitch & Lock Stitch & Chain Stitch & Chain Stitch \\
\hline Class & 301 & 601 & 401 \\
\hline Speed(rpm) & 1000 & 1000 & 1000 \\
\hline SPI & 11 & 11 & 17 \\
\hline & $\begin{array}{l}\text { Lap felled } \\
\text { Seam }\end{array}$ & $\begin{array}{l}\text { Lap Felled } \\
\text { Seam }\end{array}$ & Lap felled Seam \\
\hline Seam & DB*1 & UY128 GAS & UY 128 GAS \\
\hline Needle & $14 / 90$ & $14 / 90$ & $14 / 90$ \\
\hline Needle Size & 30 & 30 & 30 \\
\hline Total No of sample Stitched & \multicolumn{3}{|l}{} \\
\hline
\end{tabular}

\subsection{Sewing Thread Selection For Study}

The Sewing thread selected is $100 \%$ spun polyester thread for making all the samples the details are given below table 3.3 sewing thread.

Table 3.3 Sewing Thread Selection For Study

\begin{tabular}{|c|c|c|}
\hline S.No & RAW MATERIAL & SPECTFICATION \\
\hline 1 & Material & Spun Polyester Coats - ameto ART NO $-37 \mathrm{~m}$ \\
\hline 2 & Ply & 3 Ply \\
\hline 3 & Ticket no: & 80 \\
\hline
\end{tabular}

\section{Results And Discussions}

\subsection{Seam Analysis Using Stitch Type 301}

Seam strength and elongations obtained for various types of fabrics cotton,polyester,silk,using the stitch type 301 are given table.

Table 4.1 Seam Analysis Using Stitch Type 301

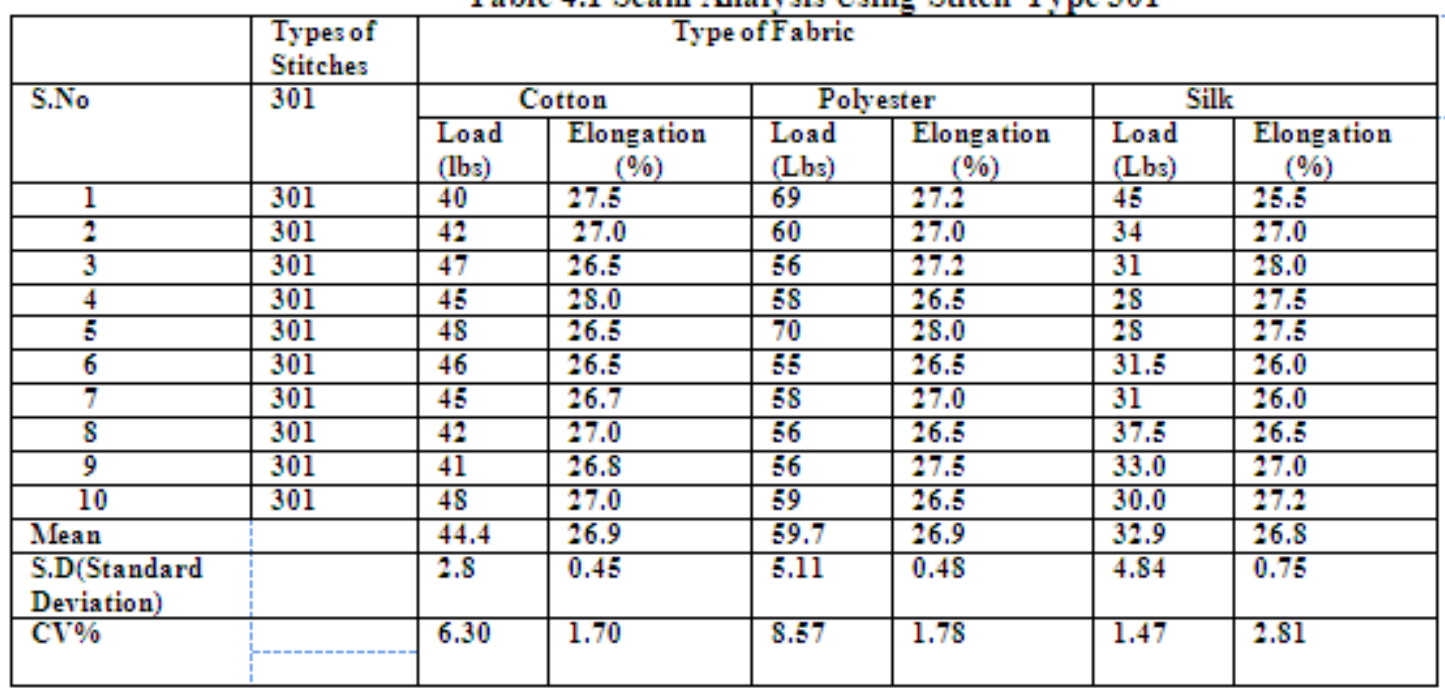

It is found from the table 4.1 that the polyester fabric is found to have higher seam strength and extension characteristics as compared to other two materials name the cotton and silk.However CV\% seam strength value is found to be on the higher side in polyester

\subsection{Seam Analysis Using Stitch Type 401}

Seam strength and elongations obtained for various types of fabrics cotton,polyester,silk, using the stitch type 401 are given table. 


\begin{tabular}{|c|c|c|c|c|c|c|c|}
\hline \multirow{3}{*}{ S.No } & \multirow{3}{*}{$\begin{array}{l}\text { Types of } \\
\text { Stitches } \\
401\end{array}$} & \multicolumn{6}{|c|}{ Type of Fabric } \\
\hline & & \multicolumn{2}{|c|}{ Cotton } & \multicolumn{2}{|c|}{ Polyester } & \multicolumn{2}{|c|}{ Silk } \\
\hline & & $\begin{array}{l}\text { Load } \\
\text { (lbs) }\end{array}$ & $\begin{array}{c}\text { Elongation } \\
(\%)\end{array}$ & $\begin{array}{l}\text { Load } \\
\text { (Lbs) }\end{array}$ & $\begin{array}{c}\text { Elongation } \\
(\%)\end{array}$ & $\begin{array}{l}\text { Load } \\
\text { (Lbs) }\end{array}$ & $\begin{array}{c}\text { Elongation } \\
(\%)\end{array}$ \\
\hline 1 & 401 & 31 & 26.6 & 75 & 26.0 & 32 & 26.0 \\
\hline 2 & 401 & 31 & 26.5 & 63 & 26.5 & 31 & 26.8 \\
\hline 3 & 401 & 37 & 26.5 & 61 & 26.0 & 33 & 26.5 \\
\hline 4 & 401 & 39 & 26.8 & 60 & 25.0 & 43 & 25.6 \\
\hline 5 & 401 & 44 & 27.5 & 68 & 26.0 & 29 & 27.7 \\
\hline 6 & 401 & 41 & 26.5 & 61 & 26.0 & 28 & 27.5 \\
\hline 7 & 401 & 33 & 26.4 & 63 & 25.5 & 30 & 26.5 \\
\hline 8 & 401 & 38 & 26.0 & 62 & 27.5 & 36 & 26.4 \\
\hline 9 & 401 & 42 & 27.0 & 62 & 28.0 & 30 & 26.8 \\
\hline 10 & 401 & 37 & 26.2 & 69 & 26.7 & 32 & 27.5 \\
\hline Mean & & 37.3 & 26.6 & 64.4 & 26.3 & 32.4 & 26.7 \\
\hline $\begin{array}{l}\text { S.D(Standard } \\
\text { Deviation) }\end{array}$ & & 4.26 & 0.4 & 4.52 & 0.84 & 4.12 & 0.65 \\
\hline $\mathrm{CV} \%$ & & 11.4 & 1.50 & 7.02 & 3.22 & 12.7 & 2.40 \\
\hline
\end{tabular}

It is found from the table 4.2 that the polyester fabric is found to have higher seam strength and extension characteristics as compared to other two materials name the cotton and silk.However CV\% seam strength value is found to be on the lower side in polyester.

\subsection{Seam Analysis Using Stitch Type 601}

Seam strength and elongation obtained for various types of fabrics cotton,polyester ,silk, using the stitch type 601 are given table.

Table 4.3 Seam Analysis Using stitch Type 601 Table 4.3 Seam Analysis Using stitch Type 601

\begin{tabular}{|c|c|c|c|c|c|c|c|}
\hline \multirow{3}{*}{$\begin{array}{l}\text { S.No } \\
\end{array}$} & \multirow{3}{*}{$\begin{array}{l}\text { Types of } \\
\text { Stitches } \\
601\end{array}$} & \multicolumn{6}{|c|}{ Type of Fabric } \\
\hline & & \multicolumn{2}{|c|}{ Cotton } & \multicolumn{2}{|c|}{ Polyester } & \multicolumn{2}{|c|}{ Silk } \\
\hline & & $\begin{array}{l}\text { Load } \\
\text { (lbs) }\end{array}$ & $\begin{array}{c}\text { Elongation } \\
(\%)\end{array}$ & $\begin{array}{l}\text { Load } \\
\text { (Lbs) }\end{array}$ & $\begin{array}{c}\text { Elongation } \\
(\%)\end{array}$ & $\begin{array}{l}\text { Load } \\
\text { (Lbs) }\end{array}$ & $\begin{array}{c}\text { Elongation } \\
(\%)\end{array}$ \\
\hline 1 & 601 & 39 & 28.0 & 49 & 26.2 & 35 & 26.5 \\
\hline 2 & 601 & 41 & 27.3 & 55 & 25.6 & 31 & 25.8 \\
\hline 3 & 601 & 33 & 26.2 & 55 & 24.8 & 33 & 26.2 \\
\hline 4 & 601 & 40 & 26.8 & 48 & 25.5 & 30 & 25.2 \\
\hline 5 & 601 & 38 & 26.7 & 43 & 24.8 & 32 & 26.2 \\
\hline 6 & 601 & 40 & 27.5 & 50 & 25.8 & 33 & 26.8 \\
\hline 7 & 601 & 37 & 26.7 & 53 & 26.2 & 30 & 25.4 \\
\hline 8 & 601 & 43 & 26.8 & 50 & 26.1 & 31 & 26.2 \\
\hline 9 & 601 & 38 & 27.6 & 44 & 27.3 & 32 & 26.1 \\
\hline 10 & 601 & 40 & 27.2 & 42 & 25.6 & 30 & 25.0 \\
\hline Mean & & 38.9 & 27.08 & 48.9 & 25.79 & 31.7 & 25.99 \\
\hline $\begin{array}{l}\text { S.D(Standard } \\
\text { Deviation) }\end{array}$ & & 2.54 & 0.50 & 4.48 & 0.69 & 1.55 & 0.55 \\
\hline CV $\%$ & & 6.54 & 1.87 & 9.16 & 2.69 & 4.89 & 2.11 \\
\hline
\end{tabular}

It is found from the table 4.3 that the polyester fabric is found to have higher seam strength and extension characteristics as compared to other two materials name the cotton and silk.However cv\% seam strength value is found to be on the higher side in polyester.

\subsection{Comparitive Analysis}

On the whole it was found that on performance wise polyester stood first next cotton and finally silk. As for as variation in seam strength is concerned silk fabric is found performance than the other materials. 


\subsection{Conclusion}

\section{Conclusion}

From the evaluation conducted the seam selected is found best suited polyester fabric for all types of stitches applied.

\subsection{Future Scope}

. The studies shall be extended to all types of blended fabric

. This studies can be done with all types of seams and stitches

\section{Acknowledgement}

I am extremely grateful to the Chairman ,Prof .A.KANAGARAJ,M.A., M. Phil., Secretary, Mrs. K.VIJAYAKUMARI,M.A.,B.ED., and Vice-Chairman Mr. K.NAVARAJ,M. Tech., of Jaya Educational Trust for having given us an opportunity to embark on this project

The most respected Principal of Jaya Engineering College, Dr.K.VIJAYARAGHAVAN, Ph.D., who has been kindling the sprit through out of the project, is thanked from the depth of the heart.

I am deeply obliged to Mr.L.NAGARAJAN .,M.Tech,Associate Professor \& HOD, Department of Textile Technology and project guide for his helpful guidance and support during the course of this project

I wish to express my warm gratitude and sincere thanks to Project Guide(Mr.V.Shunmugam) \& All Faculty Members and Lab Technicians of the Textile Department, for their valuable suggestions and help throughout the project.

\section{References}

[1]. ASTMD 6193-Standard Practice for stitches and seams.

[2]. Basic Knowledge of sewing, Sewing, Research Institute, March 20, 1999, JUKI Corporation.

[3]. How a stitching Mechanism in a sewing Machine works, Jonah Elgart.

[4]. ISO 4915: 1991 Textile - stitch types-classification and Terminology.

[5]. ISO Stitches, American and Efird, Inc.(WWW.Amefird.com)

[6]. Ready - to - wear apparel analysis, patty brown and javett Rice, Prentice Hall Publications.

[7]. U.S.Federal standard No.751a.

[8]. Stitch a seam classification and structure, stitches and seams, laing R.M. and Webster.J.

[9]. The Technology of clothing manufacture, Harold carr and Barbara Latham, Blackwell Publishing. 